\title{
Assessment of change in cervical and shoulder posture due to carriage of different weight of backpack
}

\author{
Manisha Malik, Deepa Vinay and Kumkum Pandey* \\ Department of Family Resource Management, College of Home Science, Govind Ballabh Pant University of Agri- \\ culture and Technology, Pantnagar -263153 (Uttarakhand), INDIA \\ *Corresponding author. E-mail: deepasharma1416@rediffmail.com \\ Received: October 3, 2016; Revised received: February 6, 2017; Accepted: May 27, 2017
}

\begin{abstract}
Present experimental research was planned to measure the percentage change in angle of cervical and shoulder posture of students due to carriage of different weights of backpack. For the above purpose total 30 students (15 boys and 15 girls) from the CBSE affiliated school of Meerut were selected by using the random and purposive sampling method. All the students were from the $7^{\text {th }}$ class and belonged to the age group of 10-13 years. To measure the percentage change in cervical and spinal angle in terms of extension, flexion and range of motion (ROM), six experimental conditions were planned. These experimental conditions were as (1) change in cervical and spinal region in unloaded state without backpack, (2) with backpack on right shoulder, (3) with backpack on the both shoulder, (4) with backpack of $10 \%$ reference body weight, (5) with backpack of $15 \%$ reference body weight and (6) with backpack of $20 \%$ reference body weight. These experiments were conducted by using by using inclinometer (Dualar IQ). Furthermore results were analyzed by using the mean, standard deviation (SD), range and ANOVA test.In result, it was found that the value of cervical and spinal region angles in static condition was increased with increase in weight of back pack i.e. $10 \%, 15 \%$ and $20 \%$ of reference body weight in the girls and boys. Whereas, the angle of deviation of spinal and cervical region especially flexion and extension of boys and girls in dynamic condition was found to be decreasing with increase in $10 \%, 15 \%$ and $20 \%$ body weight of backpack. Based on current study results, a schoolbag should not be more than $5 \%$ or body weight among the girl students and $10 \%$ of body weight among boy students. Otherwise, it will be a risk factor for postural problems either immediately or during adulthood that needs to be cured urgently.
\end{abstract}

Keywords: ANOVA, Cervical, Extension, Flexion, Range of motion

\section{INTRODUCTION}

Within developed nation backpacks are commonly used items in school system and, use of it among schoolchildren has become the most popular means of transporting belongings to and from school (Kim and Yoo, 2013). There are various styles of bag such as shoulder bags and backpacks etc. and various styles of carrying a bag are used by the students in their daily life (Osamaet al., 2016).Children's are introduced to the concept of carrying a backpack as early as 2 years of age. Decreased availability of school lockers, increased home work, larger textbooks and other objects carried to school has prompted the increase use of backpack that has lead to the increase in weight and duration of backpack carriage (Frances, 2011). While carrying a bag and walking, the body is subjected to physical stress owing to the weight of the bag, and the body is either mechanically or physiologically influenced, which affect dynamic balance and change the posture of the body (Lucas et al., 2013, and Ozgület al., 2012). Carrying a backpack in an incorrect manner can also cause various biomechanical, physiological and neuromuscular disorders that may reduce physical performance (Son, 2013 and Brackley et al., 2009) of the growing students. However, there is growing public concern that overloaded and repeated carrying of heavy loads places additional stress on rapidly growing children's and adolescents spinal structure, making them prone to postural change which may lead to the development of back pain, musculoskeletal injuries (Heather, 2009) along with change in spine curvature (Son, 2013). Therefore, load carrying with irregular spinal growth pattern can affect the adolescent posture and make the adolescents more susceptible to injuries (Mohan et al., 2007). Effectively, the relative load carried by school children should be expressed as percent of body weight ( $\%$ BW) and the load weight must be in a range between $10 \%$ and $22 \%$ of body weight. A school bag limit of $10 \%$ to $15 \%$ of body weight has been suggested as a maximum load for school students (Brackley and Stevenson, 2004). However a recent study carried among 13-14 years old children found significant changes in body posture, rating of perceived exertion and muscular strain when school bag load reaches $10 \%$ or their body weight (Mackie and 
Legg, 2008).Therefore in today's life there is an urgent need to to raise awareness among the teachers, medical professionals and parents over the increasing incidents of backpack related injury in school children (Iyer, 2000)

Few Indian researchers also have focused on the impact of load carried on postural angles in high school children. But there is lack of information regarding \% or backpack load carried by children on posture in India. Thus the present study was planned with the objective to determine the effect of increasing magnitude of load on cervical and shoulder postural angles and to compare the $10 \%, 15 \%$ and $20 \%$ body weight backpack with unloaded condition.

\section{MATERIALS AND METHODS}

Present experimental research was planned to measure the percentage change in angle of cervical and shoulder posture. For these purpose total 30 students (15 boys and 15 girls) from the CBSC affiliated school of Meerut were selected by using the random and purposive sampling method. All the students were from $7^{\text {th }}$ class and falls under the age group of 10-13 years of age. Their mean age, height and weight were $(11.97 \pm 2.5)$ years, $(138.89 \pm 7.87)$ centimeters, $(49.21 \pm 9.21) \mathrm{kg}$ with a backpack weight of $4.3 \pm 1.21$ $\mathrm{kg}$. This study was approved by the local research ethical committee. To know the percentage change in cervical and shoulder angle in terms of extension, flexion and range of motion (ROM), measurements were taken in 6 experimental conditions as (1) cervical and spinal region in unloaded state without backpack, (2) with backpack on right shoulder, (3) with backpack on the both shoulder, (4) with backpack of $10 \%$ reference body weight, (5) with backpack of $15 \%$ reference body weight and (6) with backpack of $20 \%$ reference body weight.Results were analyzed by using the mean, standard deviation (SD), range and ANOVA test.

For carrying out above stated experiment instrument i.e. inclinometer (Dualar IQ) was used which consists of primary and secondary inclinometer, joined with the help of connecting cable. Besides this three straps of velcro were used for tying both of the inclinometers in cervical and shoulder region to record the experiment value. The data regarding extension and flexion was recorded in this digital machine in both dynamic and static mode, which records up-to six repetitions per test and up to 19 tests. It works as both dual and single inclinometer. To ensure proper orientation and accurate measurement, the narrow side of the primary and secondary inclinometer was oriented as close to perpendicular to the floor as possible. The primary inclinometer was positioned superior to the secondary inclinometer.

For measuring the inclination of spine the subject stands upright in neutral position, first place the sensor on a wall and press the start/stop button to establish zero. Then place the primary sensor at $\mathrm{T} 1$ and the secondary sensor over the sacral midpoint. The subject flexes maximally and extends maximally and the inclinometer records the angles. Inclinometer has been found to be more reliable than goniometer for measurement of spinal motions as goniometry requires alignment of on axis with the center plan of a joint. Inclinometer, in contrast, can be simply tested against tested against a body part for assessment of motion about an axis relative to the constant of gravity (ICA Best Practices \& Practice Guidelines, 2013).

Besides above the value of angle of difference in static position was compared with the standard values given by Sengupta (2014) and the value of extension and flexion in dynamic position was compared according to the guides of American Medical Association (2013).

\begin{tabular}{cccc}
\hline Regions & $\begin{array}{c}\text { Primary } \\
\text { value }\end{array}$ & $\begin{array}{c}\text { Secondary } \\
\text { value }\end{array}$ & $\begin{array}{c}\text { Angle of } \\
\text { difference }\end{array}$ \\
\hline Cervical & $30^{0}$ & $30^{0}$ & $10^{0}$ \\
Spine & $90^{\circ}$ & $30^{\circ}$ & $60^{\circ}$ \\
\hline
\end{tabular}

Angle of deviation of girls and boys in dynamic condition (American Medical Association's $5^{\text {th }}$ edition

\begin{tabular}{ccc}
\hline Regions & Flexion & Extension \\
\hline Cervical & 50 & 60 \\
Thoracic & 25 & 25 \\
Lumber & 60 & 25 \\
Spine & 85 & 50 \\
\hline
\end{tabular}

\section{RESULTS AND DISCUSSION}

Angle of deviation of cervical and spinal regions of girls and boys in static condition: As per the findings it was concluded from table 1 that the value of range of motion of cervical region of girls in case of without backpack was $60.04^{0}$, which was equal to the standard value. As the girls carried their own backpacks on right shoulder and both shoulder, range of motion was less than the normal value $\left(54.32^{0}, 53.04^{0}\right)$. It was also found that the value of ROM decreased when the girls carried 10 percent, 15 percent and 20 percent of the reference body weight $\left(50.57^{0}, 48.64^{\circ}\right.$ and $47.24^{0}$ respectively). ANOVA was used to know the effect of load on different angles with $\mathrm{P}$ value $<0.001$ and $\mathrm{F}$ value 13.83. When the unloaded state was compared with the carriage position on right shoulder and both shoulder, it was found significant with $\mathrm{P}$ value 0.002 and $<0.001$. The unloaded condition was also found significant, while the girls carried the backpack weight 10 percent, 15 percent and 20 percent of reference body weight with $\mathrm{P}$ value $<0.001$ in all the conditions. Thus it was depicted that there was more forward inclination of neck in girls as the weight of backpack was increased. Tousignant et al. (2000) found inclinometer as valid for measurement for measuring flexion and extension. 
While table 2 revealed that boys, cervical range of motion values in all the conditions were less than the normal value as $53.15^{\circ}, 48.37^{0}, 48.30^{\circ}, 41.31^{\circ}, 45.47^{0}$ and $44.07^{\circ}$ respectively. Analysis of variance was applied (table 3) with $\mathrm{P}$ value 0.004 and $\mathrm{F}$ value 3.765 . The unloaded state was found to be non significant with carriage position, while found to be significant with static loading of 10 percent, 15 percent and 20 percent reference body weight with $\mathrm{P}$ value 0.002 , $<0.001$ and $<0.001$ respectively.(Plate 1 )

Similar to girls, these values clearly indicated that boys had also small angle due to increase in load which showed more forward inclination of cervical region.

Angle of deviation of spine region of girls and boys in static condition: It was clear from the table 4that the spinal range of motion in case of girls was more than the standard value $\left(10^{\circ}\right)$ and the ROM value continuously increased as the weight of backpack increased $\left(17.93^{\circ}, 16.33^{\circ}, 23.97^{\circ}, 25.19^{0}, 31.91^{\circ}\right.$ and $33.33^{0}$ respectively). Analysis of variance (table 6) was used to know the significance of values. The unloaded condition found significantly different with static loading of 10 percent, 15 percent and 20 percent reference body weight with $\mathrm{P}$ value $0.009,<0.001$ and $<0.001$. Load carriage on right shoulder was also found significant with loading on both shoulder, 10 percent, 15 percent and 20 percent body weight with $\mathrm{P}$ value 0.006 , $0.002,<0.001$ and $<0.001$ respectively. The value of range of motion on both shoulders was significantly different to 15 percent and 20 percent reference body weight with $\mathrm{P}$ value 0.005 and $<0.001$. According to Castro et al. (2000) criteria such as age, sex body weight and athletic activity also influence range of motion of the spine.

As table 5 depicted the percentage change in angle of the boys in static. The findings showed that the value of ROM was less (i.e. 5.48) then the normal value in without backpack condition and slightly equal to standard value $\left(10.94^{\circ}\right)$. While in other treatments the value of range of motion increased due to carry on right shoulder as well as increase in weight of 10 percent, 15 percent and 20 percent reference body weight by $11.03^{\circ}, 11.48^{0}, 16.54^{\circ}$ and $15.46^{\circ}$ respectively. It was revealed from table 6 that the mean value of range of motion in unloaded state was significantly different with all the other conditions with $\mathrm{P}$ value $<0.001$, while $10 \%$ body weight was also found significant with $20 \%$ of body weight $(\mathrm{P}$ value $=0.005)$. So it can be concluded that while measuring the spinal angle of difference, the value of thoracic angle was increased while the value of sacral angle decreased or equal to the standard value. It would lead to thoracic kyphosis in children.

In result of table 7it was found that the mean value of flexion was decreased while the girls carried the backpack of 10 percent, 15 percent and 20 percent body weight $\left(43.27^{0}, 39.12^{0}\right.$ and $\left.37.63^{\circ}\right)$ in comparison to standard value $50^{\circ}$. Similar to boys (table 8 ) the mean value of flexion was also decreasing $\left(32^{0}, 31^{0}, 25^{0}\right)$ with the increasing in percentage body weight of backpack in relation to standard value $50^{\circ}$.

Thus, when there is flexion (or forward bending) in T1 thoracic region a compensatory lumbar extension is required to maintain an upright posture with horizontal gaze. Changes in any aspect of postural alignment, from the feet to the head, require compensations throughout the body (Oatis, 2004).

As it was depicted from table 7 and 8 that the standard value of extension was $60^{\circ}$, while extension values of both girls and boys were negative in all the treatments except in case of girls with 10 percent reference body weight $\left(2.57^{0}\right)$. The negative values showed that there was no extension only flexion was present. The children were inclined in forward direction only.

The $\mathrm{P}$ value was not found significant with any treatment in both boys and girls.

Angle of deviation of spine region of girls and boys in dynamic condition: As per the findings of table 9, it was revealed that normal value of flexion of spine was $85^{\circ}$, while in girls the flexion values were $29^{\circ}$, $39.30^{\circ}$ and $38.45^{\circ}$ with respect to 10 percent, 15 percent and 20 percent of body weight. However in boys table 10 revealed that these values were $21^{\circ}, 33^{\circ}$ and $44.96^{\circ}$ respectively.

Table 11 revealed that in girls the flexion value did not found significant with any treatment. In contrast significant difference was found between 10 percent and 15 percent reference body weight with $P$ value 0.019 as well as the 10 percent reference body weight was significantly different with 20 percent reference body weight with $\mathrm{P}$ value $<0.001$. The result of one study suggested that carrying school bag weighing $10 \%$ of body weight would be too heavy for the students (Chansirinukor et al., 2001). Some researchers reported that some adolescent students are still quite young to carry heavy bag weight in proportion to their body weight (Mackie, 2006; Dockrell et al., 2006; Al, 2011; Abrahams et al., 2001).

Whereas the normal value of extension was $50^{\circ}$. In case of girls mean values of flexion were $17^{\circ}$ and $12.22^{\circ}$ while carrying 10 and 15 percent of reference body weight, but as the backpack weight increased up to 20 percent of body weight, the mean value of extension decreased to $9^{0}$. It may be because the girls fixed their upper part of spine at (T1) point. No significant difference was found with different treatments in girls. Several studies showed that gender is a significant factor for change in angle and development back pain among school children. Girls were more likely to report such symptoms and disability than boys of the same age (Mackie, 2006; Haselgrove et al., 2008 ; Ismail et al., 2009; Dianat et al., 2011; Khalil, 2012; Rai et al., 2013). This might be related to physiological differences between the two genders. Navuluri et 


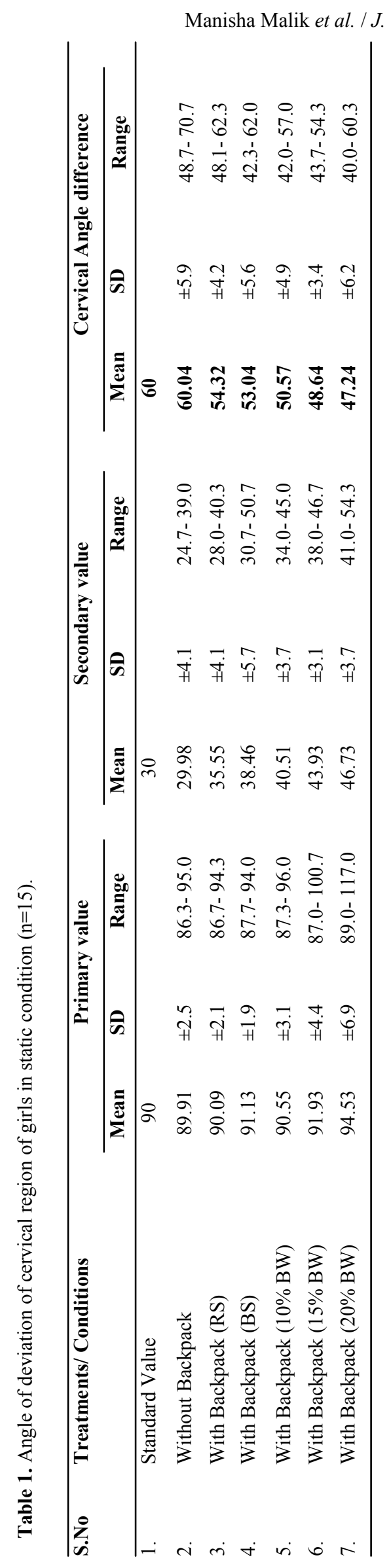

(2). $1272-1281$ (2017)

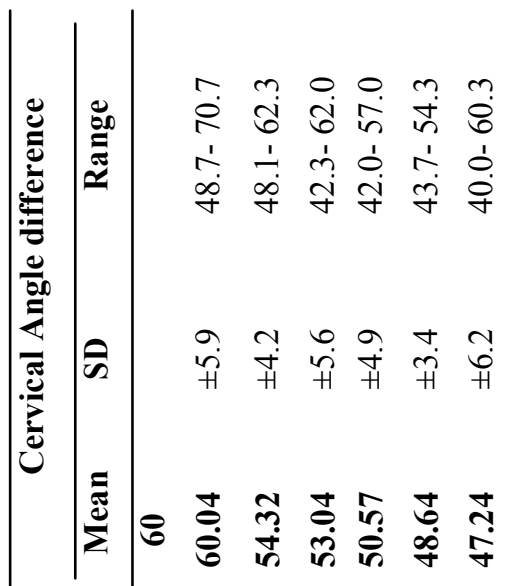

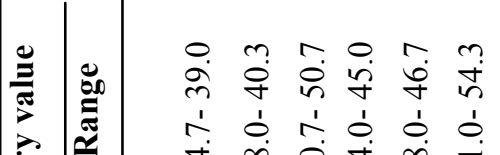

च

ֻัँ

क ت च

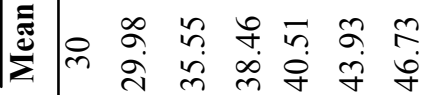

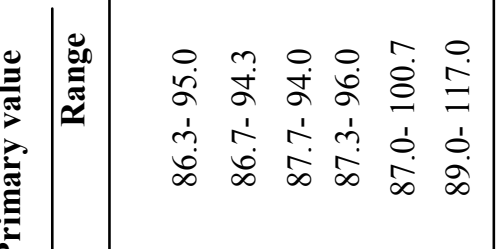

音

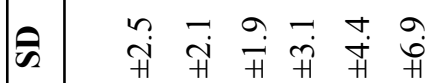

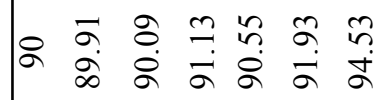

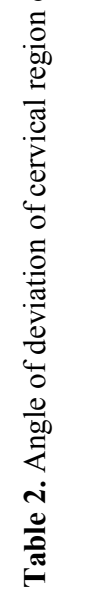




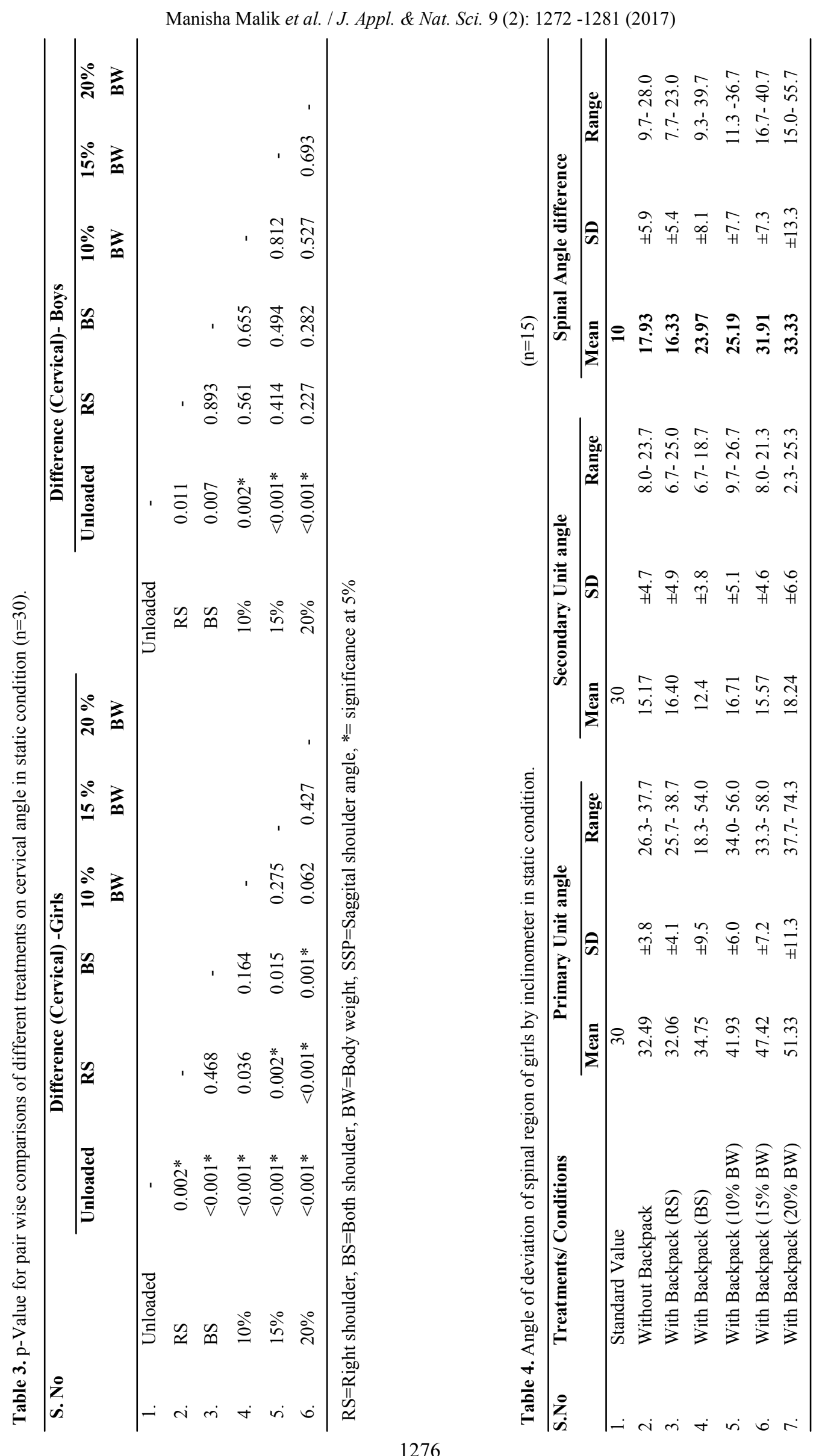




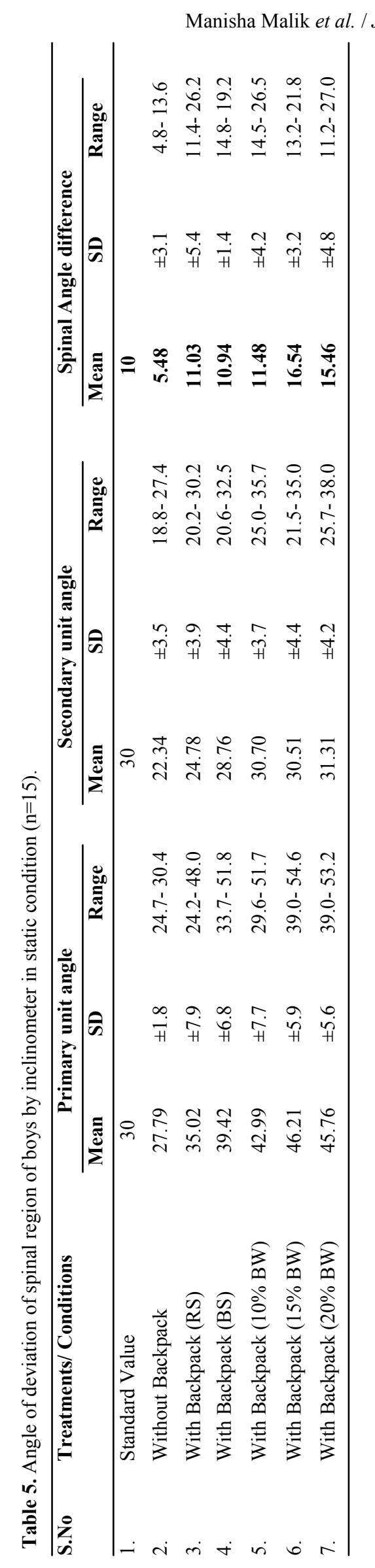

(2): $1272-1281$ (2017)

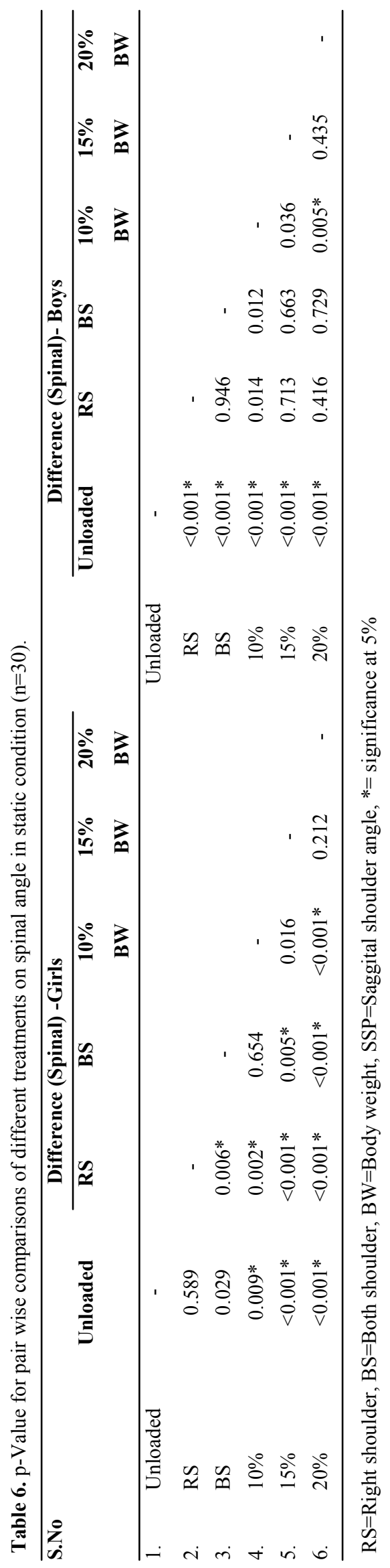




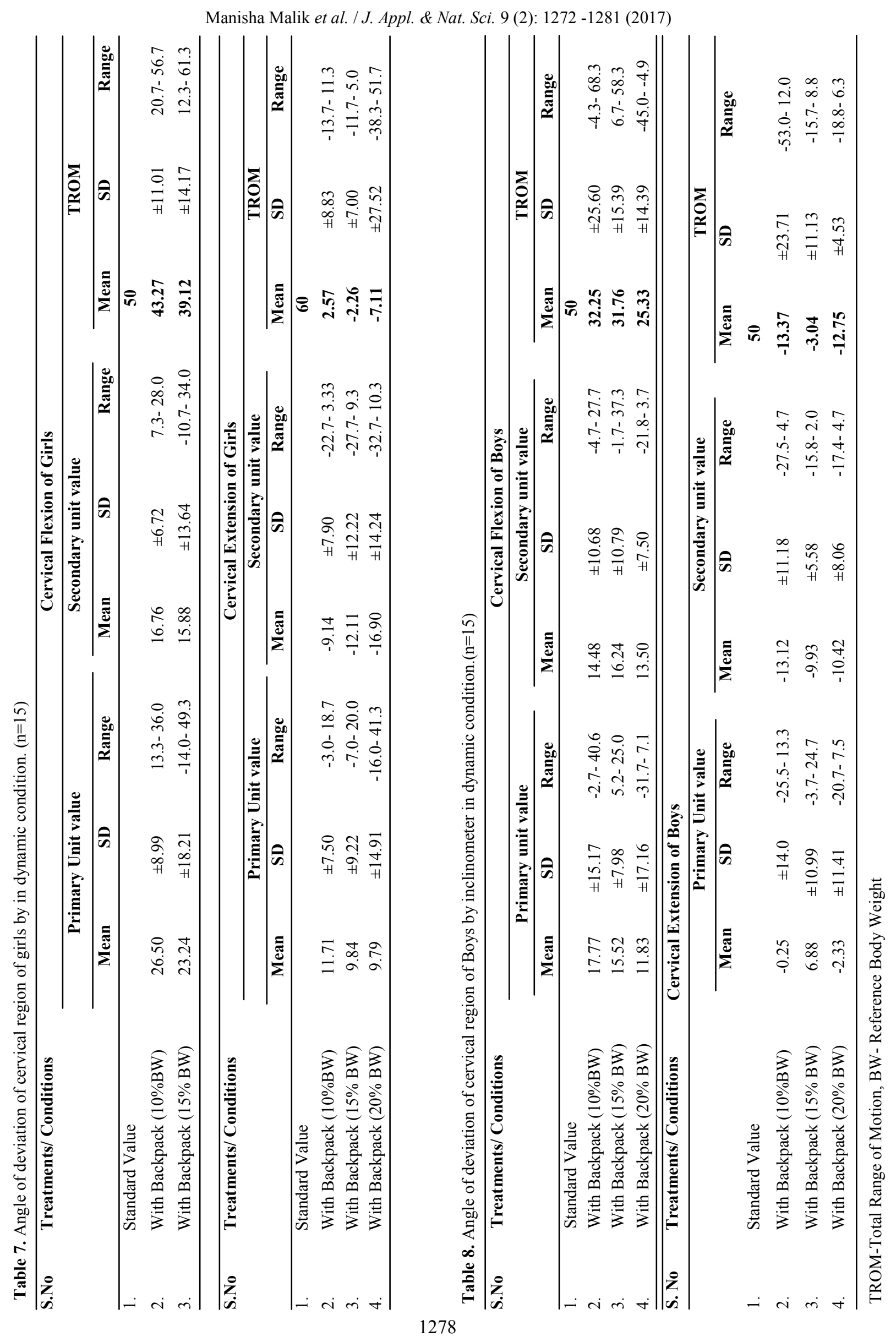




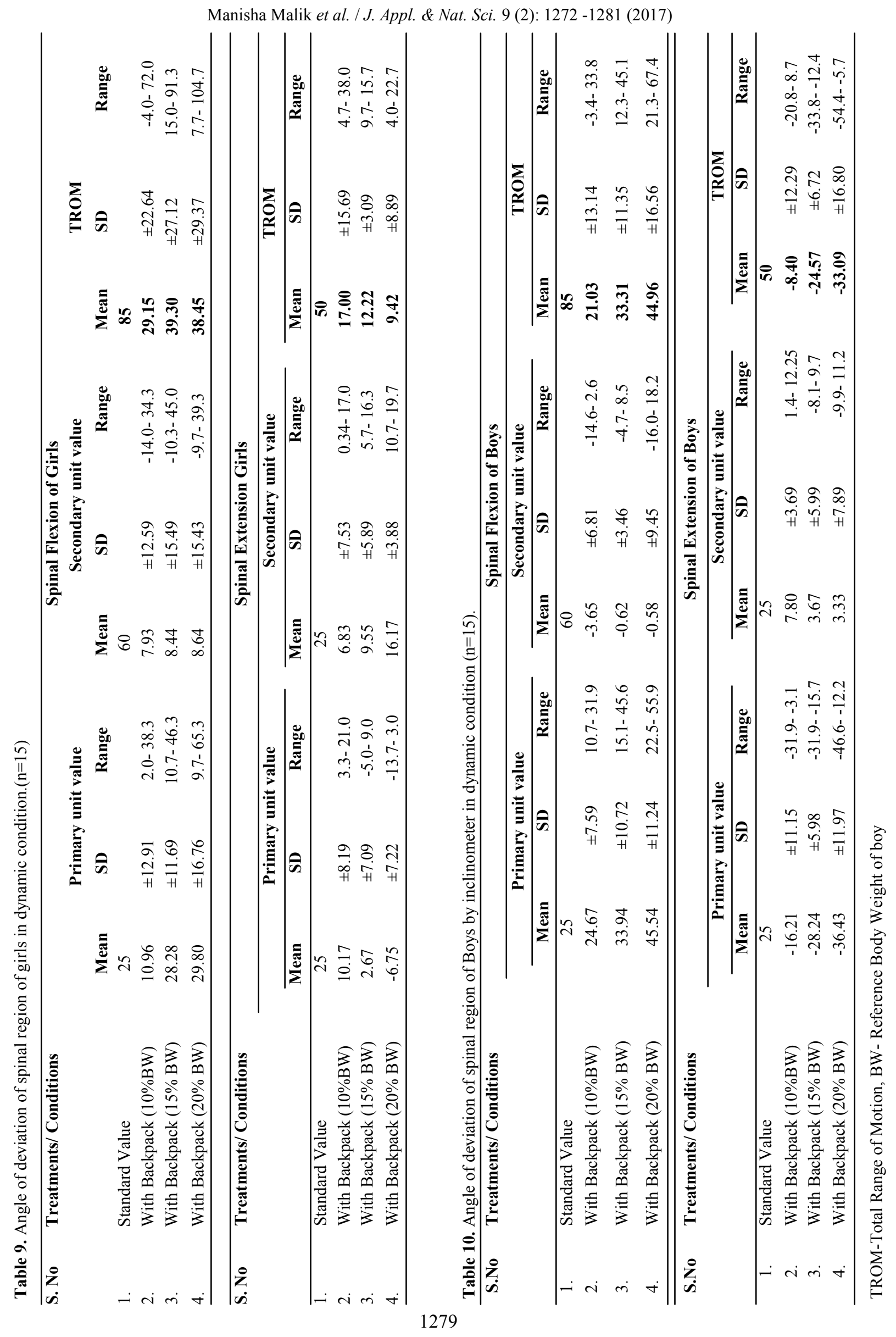


Table 11. $\mathrm{p}$-Value for pair wise comparisons of different treatments on spinal angle in dynamic condition. $(\mathrm{n}=30)$

\begin{tabular}{|c|c|c|c|c|c|c|c|c|c|c|c|c|c|c|}
\hline \multirow[t]{3}{*}{ S.No } & & \multicolumn{6}{|c|}{ Spinal TROM -Girls } & \multicolumn{7}{|c|}{ Spinal TROM - Boys } \\
\hline & & \multicolumn{3}{|c|}{ Flexion } & \multicolumn{3}{|c|}{ Extension } & & \multicolumn{3}{|c|}{ Flexion } & \multicolumn{3}{|c|}{ Extension } \\
\hline & & $\begin{array}{l}10 \% \\
\text { BW }\end{array}$ & $\begin{array}{r}15 \% \\
\text { BW }\end{array}$ & $\begin{array}{c}20 \% \\
\text { BW }\end{array}$ & $\begin{array}{l}10 \% \\
\text { BW }\end{array}$ & $\begin{array}{c}15 \% \\
\text { BW }\end{array}$ & $\begin{array}{c}20 \% \\
\text { BW }\end{array}$ & & $\begin{array}{l}10 \% \\
\text { BW }\end{array}$ & $\begin{array}{l}15 \% \\
\text { BW }\end{array}$ & $\begin{array}{c}20 \% \\
\text { BW }\end{array}$ & $\begin{array}{l}10 \% \\
\text { BW }\end{array}$ & $\begin{array}{l}15 \% \\
\text { BW }\end{array}$ & $\begin{array}{l}20 \% \\
\text { BW }\end{array}$ \\
\hline 1. & $10 \%$ & - & & & - & & & $10 \%$ & - & & & - & & \\
\hline 2. & $15 \%$ & & - & & & - & & $15 \%$ & $0.019^{*}$ & - & & 0.027 & - & \\
\hline 3. & $20 \%$ & & & - & & & - & $20 \%$ & $<0.001^{*}$ & $0.026^{*}$ & - & $<0.001^{*}$ & 0.436 & - \\
\hline
\end{tabular}

$\mathrm{BW}=$ Reference body weight, TROM= total range of motion, ${ }^{*} 5 \%$ level of significance

al, (2006) found that the correlation between pain and backpack weight per body mass index among girls was positive and significant, but negative and nonsignificant among boys and (Brackley, 2004and Qallaf 2011). On the other hand, some other researchers found no significant difference between boys and girls in this aspect (Dianat et al., 2011).

It was also clear from table 11 that the boys mean values of extension in all the treatments were negative. It means there was no extension. There was found a significant difference between 10 percent reference body weight with 20 percent of reference body weight with $\mathrm{P}$ value $<0.001$.

\section{Conclusion}

In conclusion it was found that the value of cervical and spinal region angles in static condition was increased with increase in weight of back pack i.e. $10 \%$, $15 \%$ and $20 \%$ of reference body weight in the girls and boys. Whereas the angle of deviation of spinal and cervical region especially flexion and extension of boys and girls in dynamic condition was found to be decreasing with increase in \% body weight of backpack. Thus, this condition calls for the immediate intervention in designing of the backpack of children or develop some guidelines which will be able to reduce the load of books of students and that must be followed by the schools.

\section{REFERENCES}

Abrahams, S., Ellapen, T.J., Van, H.J. and Vanker, R. (2011). The impact of habitual school bag carriage on the health of pubescent scholars. African Journal for Physical, Health Education, Recreation \& Dance, 2 (17): 763-772

Al, and Qallaf, F.F. (2011). Influence of backpack weight on school girls' balance and musculoskeletal pain. King Saud University.

American Occupational Therapy Association http:// www.aota.org/2006.

Brackley, H.M. and Stevenson, J.M. (2004). Are children's backpack weight limits enough?: A critical review of the relevant literature. Spine, 29: 2184-2190

Brackley, H.M., Stevenson, J.M. and Selinger, J.C. (2009). Effect of backpack load placement on posture and spinal curvature in prepubescent children. Work, 32: 351360
Castro, W.H., Sautmann, A., Schilgen, M. and Sautmann, M. (2000). Noninvasivethree dimensional analysis of cervical spine motion in normal subjects in relation to age and sex. An experimental examination.Spine, 25(4):443 $-449$

Chansirinukor, W., Wilson, D., Grimmer, K. and Dansie, B. (2001). Effects of backpacks on students: measurement of cervical and shoulder posture. Australian Journal of physiotherapy, 31(47):110-6

Dianat, I., Javadivala, Z. and Allahverdipour, H. (2011). School bag weight and the occurrence of shoulder, hand/wrist and low back symptoms among Iranian elementary schoolchildren. Health promotion perspectives, 25(1):76-85

Dockrell, S., Kane, C. and O'keefe, E. (2006). Schoolbag weight and the effects of schoolbag carriage on secondary school students. Ergonomics, 9:216-22

Frances, E.K. (2011). Postural compensations and subjective complaints due to backpack loads and wear time in schoolchildren aged 8-11, Abstract of a dissertation at the University of Miami. August, page no 25-107

Haselgrove, C., Straker, L., Smith, A., O'Sullivan, P., Perry, M. and Sloan, N. (2008). Perceived school bag load, duration of carriage, and method of transport to school are associated with spinal pain in adolescents: an observational study. Australian Journal of Physiotherapy, 31 (54):193-200

Heather, M.B., Joan, M.S. and Jessica, C.S. (2009). Effect of backpack load placement on posture and spinal curvature in prepubescent children. Work, 32:351-360

ICA Best Practices \& Practice Guidelines, (2013). Assessment Measures inChiropractic, International Chiropractors Association, Arlington VA. Pp. 63-131.

Ismail, S.A., Tamrin, S.B. and Hashim, Z. (2009). The association between ergonomic risk factors, rula score, and musculoskeletal pain among school children: a preliminary result. Global Journal of Health Science, 1(1):73

Iyer, S.R. (2000). Musculoskeletal pain in school children. $I n$ : Proceedings of theInternational Ergonomics Association, Human Factors Ergonomics Society Congress Washington, DC. 5: 419-422

Khalil and AL, Q.A. (2012). The influence of backpacks on students backs a cross-sectional study of schools in Tulkarm district, 2012, National University.

Kim, M.H. and Yoo, W.G. (2013). Effect of the spacing of backpack shoulder straps on cervical muscle activity, acromion and scapular position, and upper trapezius pain. J Phys Ther Sci., 25: 685-686

Lucas, C., Pérez, S.P., Bush. M, et al. (2013). Effects of different backpack loads in acceleration transmission 
during recreational distance walking. J Hum Kinet, 37: 81-89

Mackie, H.W. (2006). Schoolbag carriage: design, adjustment, carriage duration and weight: a thesis presented in fulfilment of the requirements for the degree of Doctor of Philosophy in Ergonomics at Massey University, Palmerston North, New Zealand.

Mackie, H.W. and Legg, S.J.(2008). Postural and subjective responses to realistic schoolbag carriage. Ergonomics, $51: 217-231$

Mohan. M., Singh, U. and Quddus, N. (2007). effect of backpack loading in Indian school children. Ind J Physiotherap \& Occup Therap, 1: 1-9

Navuluri, N. and R.B. Navuluri. (2006). Study on the relationship between backpack use and back and neck pain among adolescents. Nursing \& Health Sciences, 8: 208215

Oatis, C.A. (2004). Kinesiology: the mechanics and path mechanics of humanmovement. Lippincott, Williams \& Wilkins.
Osama R.A., Hamada, A. H., Ali, S., Wael, S. and Hoda Z. (2016). Effect of backpack shoulder straps length on cervical posture and upper trapezius pressure pain threshold. J Phys Ther Sci., 28(9): 2437-2440

Ozgül, B., Akalan, N.E., Kuchimov, S. et al. (2012). Effects of unilateral backpack carriage on biomechanics of gait in adolescents: a kinematic analysis. Acta Orthop Traumatol Turc, , 46: 269-274

Rai, A. and Agarawal, S. (2013). Back problems due to heavy backpacks in school children. IOSR Journal of Humanities and Social Science, 10: 01-00

Sengupta, D.K. (2014). Spinopelvic Balance Journal of Bone and Joint surgery, Reviews, 2(8):4

Son, H.(2013). The effect of backpack load on muscle activities of the trunk and lower extremities and plantar foot pressure in flatfoot. J Phys Ther Sci, 25: 1383-1386

Tousignant, M., de Bellefeuille, L., O'Donoughues, S. and Grahovac, S. 2000. Criterion validity of the cervical range of motion (CROM) goniometer for cervical flexion and extension. Spine, 25: 324-330 